\title{
Servikal diskojenik ağrılar
}

\section{Cervical discogenic pains}

\author{
Oğuz Cebesoy, Levent Konukoğlu
}

Medicalpark Gaziantep Hastanesi Ortopedi ve Travmatoloji Kliniği, Gaziantep

\begin{abstract}
Servikal intervertebral disk hastalıkları, tüm spinal intervertebral disk hastalıkları içinde \%36 oranıyla en sık görülen ikinci hastalıktır. Her beş ortopedik muayeneden bir tanesinin servikal diskojenik ağrı ile ilgili olduğu ve bu ağrıların da \%75 kadarının ise C5-C6 ve C6-C7 kökenli olduğu saptanmıştır. Kadınlarda biraz daha sık görülen bu hastalık grubu, kontakt sporlarında görülen yaralanmaların da \%2-3 kadarını oluşturmaktadır. Servikal omurga hareketleri içinde, sagittal planda fleksiyon ve ekstansiyon, koronal planda lateral fleksiyon, horizontal planda ise rotasyon yer alır. Genelde, lateral fleksiyon ve rotasyon birlikte görülür. Diğer hareketler ise protrüzyon ve retraksiyondur. Kötü pozisyonda uzun süre oturma, sık sık yapılan boyun fleksiyonu, ani hareketler ve travma, servikal disk hastalıklarında başlıca predispoze faktörlerdir. Boyun ağrılı bir hasta değerlendirilirken, doğru bir öykü esastır. Ciddi bir potansiyel problem ve/veya bu problemin spinal kaynaklı olup olmadığını ayırt etmek, tedavi açısından son derece önemlidir. Fiziksel incelemede, gözlem, elle muayene ve motor-duyu-refleks muayeneleri mutlaka yapılmalıdır. Direkt grafiler, manyetik rezonans (MR) görüntüleme ve diğer yardımcı testler tanıda önemli rol alır. Çoğu servikal diskojenik ağrı, agresif konservatif tedaviyle çözümlenebilir. İlaç olarak non-steroid anti-inflamatuvar ilaçlar (NSAii), kısa süreli steroidler, narkotik olmayan analjezikler ve kısa süreli narkotikler kullanılabilir. Kapsamlı bir rehabilitasyon programı ve selektif enjeksiyonlarla durumlarında iyileşme olmayan hastalara, cerrahi girişim önerilmelidir. Servikal radikülopatisi olan hastaların prognozu uygun tedaviyle mükemmeldir. Hastaların \%80-90'ında operasyon dışı tedaviler etkili olur.
\end{abstract}

Anahtar sözcükler: diskojenik ağrı; radikülopati; servikal omurga
Cervical discogenic pain is the second most common disease among all spinal intervertebral disc diseases with a rate of $36 \%$. One of every five orthopedic examinations is associated with cervical discogenic pain, and $75 \%$ of these pains are of C5-C6 and C6-C7 origin. This disease group which is more common in females, accounts for $2-3 \%$ of injuries in contact sports. Cervical spine movements include flexion and extension in sagittal plane, lateral flexion in coronal plane, and rotation in horizontal plane. Lateral flexion and rotation are commonly seen together. Other cervical movements are protrusion and retraction. Prolonged sitting in a bad position, frequent neck flexion, sudden movements and trauma are the predisposing factors in cervical disc diseases. A good history is essential for assessing a patient with cervical pain. It is very important for the treatment to distinguish whether the problem is spinal origin and/or related with a serious problem. Inspection, palpation, and motor-sensory-reflex examinations should be performed at the physical examination. Direct radiographs, MRI and other special tests play important role in diagnosis. Most of the cervical discogenic pains can be treated by aggressive conservative treatment methods. NSAIDs, short-acting steroids, non-narcotic analgesics and short-acting narcotics may be used for medication. Selective surgery should be recommended for non-healing patients with selective injections, and comprehensive rehabilitation program. The prognosis of patients with cervical radiculopathy is excellent with appropriate treatment. Non-operative treatment options are effective in $80-90 \%$ of patients.

Key words: discogenic pain; radiculopathy; cervical spine

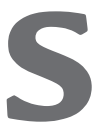
ervikal intervertebral disk hastalıkları, tüm spinal intervertebral disk hastalıkları içinde \%36 oranıyla ikinci sırada yer almaktadır. Illk sırada \%62 oranıyla lomber vertebral disk hastalıkları yer alır. Servikal disk problemleri, lomber disk problemlerinden daha az kısıtlılığa yol açar ve onlar kadar sık işgücü kaybına neden olmaz. ${ }^{[1,2]}$
Her beş ortopedik muayeneden bir tanesinin servikal diskojenik ağrı ile ilgili ve bu ağrıların da \%75 kadarının C5-C6 ve C6-C7 kökenli olduğu saptanmıştır. En sık tutulan sinir kökünün $\mathrm{C7}$ olduğu görülmüştür. ${ }^{[3]}$ Servikal diskojenik ağrı sendromu, öncelikle proksimal semptomlarla başlayıp, zamanla distal bölgeleri etkileyerek brakiyalji tipi ağrıya yol açar.

- Illetişim adresi: Prof. Dr. Oğuz Cebesoy, Medicalpark Gaziantep Hastanesi Ortopedi ve Travmatoloji Kliniği, Gaziantep Tel: 0532 - 3975652 e-posta: ocebesoy@yahoo.com

- Geliș tarihi: 5 Nisan $2017 \quad$ Kabul tarihi: 5 Nisan 2017 


\section{EPIDEMIYOLOJi}

Servikal intervertebral disk hastalı̆̆ı, tüm disk hastalıkları içinde \%36 görülme oranına sahip olup kadınlarda daha sık görülür. Genç hastalarda akut ataklarla eğri veya çarpık boyun şeklinde ortaya çıksa da, insidans $45-50$ yaş grubunda artar. Sporla ilişkili yaralanmaların \%2-3 kadarında görülmekle birlikte, spor gruplarının içerisinde de en fazla futbol, güreş, dalış, sörf gibi kontrolün zor olduğu dallarda görülürr. ${ }^{[4]}$

İstatistiksel tahminlere göre, sporcularda kuadripleji oranı 1/7.000 ila $1 / 58.000$ arasında değişim göstermektedir. ${ }^{[5]}$ Bir başka çalışmada ise, sporcularda servikal travmaya bağlı olarak her yıl 10'dan az sayıda kalıcı hasar oluşan yaralanma görüldüğü bildirilmiştir. ${ }^{[6]}$

\section{FONKSIYONEL ANATOMI}

Servikal omurga, baş ile gövde arasında geniş bir hareket açıklığı sağlar. Hareket kontrolü ve omurgaya gelen yükün dağılımı için belli bir stabilite ve fleksiyon derecesi gerekmektedir. C1-C2 arasında (üst kompleks) ve C3-C7 arasında (alt kompleks) büyük anatomik ve fonksiyonel farklılıklar olabilir. Oksiput ve T1 arasında sekiz hareketli segment bulunur. $C 1$ ve $C 2$ arasında disk bulunmayıp, ilk intervertebral disk C2C3 arasındadır.

İntervertebral disk, dişta annulus fibrozus ve içte nükleus pulpozustan oluşur. İntervertebral diskler anteriorda biraz daha ince olup, bu durum servikal lordoz oluşumuna katkıda bulunur. En ince disk C6-C7 arasındadır. Nükleus pulpozus ve annulus fibrozusun iç yarısı avasküler olup diffüzyonla beslenir. ${ }^{[7]}$

Annulus fibrozusun özellikle $1 / 3$ dış kısmı, sinovertebral ve vertebral sinirlerce innerve edilir. Sinovertebral sinir, ventral ramustan (somatik kök) çıkar. Vertebral sinir ise birincil olarak sempatik sinir sisteminden köken alır. Vertebral sinirin servikal ventral ramusla ilişkili olmasına rağmen aynı zamanda diskten gelen somatik afferent sinir iletiminde de rol aldığı düşünülür. ${ }^{[7]}$

Annulus fibrozustaki nosiseptörler ve mekanoreseptörler, ağrı iletiminde aracılık eder. Bu ağrı, diskin kendi yapısal bozukluklarından veya fosfolipaz A2'nin inflamatuvar etkisiyle oluşabilir. ${ }^{[7]}$ Annulusun $1 / 3$ dış kısmında yer alan pacinian korpuskülü ve golgi tendon organı, intervertebral diskten gelen propriyoseptif duyuları iletir. ${ }^{[8]}$

Erişkin bireyin servikal diski öne doğru yarım ay şeklinde bir yapıya sahiptir. Diskografi sırasında, posterior annulus üzerinde dejeneratif görünümlü çok sayıda vertikal fissür görülebilir. Ayrıca, servikal disk nükleusu lomber disk nükleusuna göre daha az santralize yerleşimlidir. Lomber vertebrada ise nükleus diskin santralinde yerleşimli ve posterior annulus servikal diske göre daha sıkıdır. Annüler fissürler ise lomber diskte sirkumfleks ve radyal yerleşimlidir.

\section{BIOMEKANIK}

Vücut hareketleri sırasında anatomik yapılarda oluşan değişikliklerle ilgili çalışmalar biyomekaniği ilgilendirir. Servikal omurga hareketleri içinde, sagittal planda fleksiyon ve ekstansiyon, koronal planda lateral fleksiyon, horizontal planda ise rotasyon yer alır. Genelde, lateral fleksiyon ve rotasyon birlikte görülür. Diğer hareketler ise, protrüzyon (baş öne doğru) ve retraksiyondur (baş arkaya doğru).

Servikal rotasyonun \%50'si, atlasın odontoid etrafinda dönmesi ve üst servikal kompleksin hareketiyle oluşur. Protrüzyon, üst servikal komplekste ekstansiyona, alt servikal komplekste ise fleksiyona yol açarken, retraksiyon tam tersi durum oluşturur. Protrüzyon ve retraksiyon sırasında, oksiput-C1 ve C1-C2 arasında hareket genişliği boyun tam fleksiyonda veya tam ekstansiyonda iken elde edilen hareket genişliğinden fazladır. ${ }^{[9]}$

Servikal vertebradaki diskler de, lomber vertebradaki gibi, hareket boyunca gelen kompresif yükü omurgaya dağıtır. Disk, annüler liflerdeki geçici uzamayla yükü dağıtarak, tüm yükün bir anda vertebraya binmesini engeller.

Asimetrik yüklenmelerde nükleus pulpozus, az yüklenme olan tarafa doğru migre olur. Servikal vertebra fleksiyon yapınca yük anteriora bineceği için, nükleus pulpozus posteriora doğru migre olur ve posterior annüler duvarda uzama gözlenir. illaveten, servikal lordoz azalır, vertebral kanal uzar ve intervertebral foramenler açilır. ${ }^{[2]}$

Boyun ekstansiyonda ise, posterior intervertebral disk bölgesine binen yük artar, nükleus anteriora doğru kayar ve anterior annüler duvar uzar, vertebral kanal kısalır, intervertebral foramenler kapanır; ${ }^{[2]}$ lateral fleksiyon ve rotasyonda ise (kombine hareket), yük fleksiyon ve rotasyon tarafına biner, nükleus zıt yöne kayar (konveks kısma doğru) ve posterolateral annüler duvar uzar. ${ }^{[2]}$

Servikal sinirler intervertebral foramenlerden çıkar. En büyük servikal foramen C2-C3 seviyesinde, en küçüğü ise C6-C7 seviyesindedir. ${ }^{[10]}$ Servikal foramenler boyun hareketleri sırasında oldukça hareketlidir. Bunlar fleksiyonda büyür, ekstansiyonda küçülür; rotasyonda ise, aynı tarafta küçülürken karşı tarafta büyür; öte yandan, kombine hareketlerde farklı değişiklikler gösterebilir. ${ }^{[11]}$ 


\section{SERVIKAL DISK AĞRISINA NEDEN OLAN FAKTÖRLER}

Kötü pozisyonda uzun süre oturma, artan yaş, ağır fiziksel işlerde çalışma, çalıştığı işte mutsuzluk ve depresyon, sık sık baş ağrısı öyküsü, sık yapılan boyun fleksiyonu, ani hareketler ve travma, başlıca predispoze faktörlerdir. Harms ve Ringdahl, asemptomatik gönüllülerde, protrüze oturma pozisyonuyla ağrıyı provoke etmeye çalışmıştır. ${ }^{[12]}$ Tüm katılımcılarda 2-15 dakika arasında boyun ağrısı oluşmuştur. Kötü pozisyondaki statik yüklenmeler, servikal omurgada ağriya neden olur, var olan ağrıyı ise daha da arttırır.

Kramer, ağrıyla gelen hastalarının çoğunda belli bir neden olmadığını bildirmiştir. ${ }^{[3]}$ Boyundaki devamI fleksiyon hareketi de predispozan faktördür. Ani ve beklenmedik hareketler, özellikle lateral fleksiyon ve rotasyon boyun ağrısı yapabilir; bu hareketler de çoğunlukla spor etkinlikleri ve kazalardan sonra gözlenir.

\section{SERVIKAL DISK YARALANMALARINDA KLINIK}

En sık semptom ve bulgu, etkilenen seviyeye, fitığın çapına ve lokasyonuna (lateral, santral ya da foraminal) bağlı olarak değişmektedir. Boyun ağrısı ve sertlik, omuza ve kola doğru yayılan tarzda olabilir. En sık boyun ağrısı (\%90), sonrasında parestezi, radiküler ağrı ve zayıflık görülür. Boyun ağrılı bir hasta değerlendirilirken doğru bir öykü esastır. Ciddi bir potansiyel problem ve/veya problemin spinal kaynaklı olup olmadığını ayırt etmek, tedavi açısından son derece önemlidir. Herhangi bir tehlike işareti yoksa, dört haftaya kadar olan semptomlarda ileri tetkiklere ihtiyaç duyulmaz; genelde zaman içerisinde düzelir.

Ağrıyı doğru karakterize edebilmek için, ağrının lokalizasyonu, ne zaman ortaya çıktığı, şekli, sıklı̆̆ı, dağılımı, ağrıyı arttıran veya azaltan faktörler öğrenilmelidir. Yansıyan ağrı ile radikülopati ağrısı ayırt edilmelidir. Yansıyan ağıı diffüz dağılım gösterirken, radikülopati ağrısı daha özgül olarak bir dermatom sahasınca yayılır. Disk dejenerasyonu olan hastalarda düşük seviyede kronik bir ağrı olabilir ve bu, haftalar içerisinde periodik olarak artabilir.

Servikal disk ağrısı, lokalize ağrı, yansıyan ağrı veya radiküler ağrı şeklinde olabilir. Mekanik ağrı sürekli veya aralıklı olabilirken, kimyasal ağrı genelde süreklidir. Servikal ağrı, baş fleksiyonda ve protrüzyonda uzun süre oturma durumlarında çok daha fazla olur. Bükme ve kıvırma hareketleri servikal ağrıyı provoke edebilir. Sık sık pozisyon değiştirmek ağrıyı azaltır. Ancak, akut ve ciddi ağrı durumlarında sabit pozisyonda durmak daha konforlu olabilir. Sabah uyanınca daha kötü hissedilen ağrı ise, uygun olmayan yastık seçimi veya uygunsuz uyuma pozisyonlarına bağlı olabilir. ${ }^{[2]}$ Cloward, 1959 yılında servikal diskografiyi kullanarak servikal yansıyan ağrı çalışmasını yayımlamıştır. [13] Yazar, servikal diskin anterolateralini uyarınca, aynı taraf skapulada ağrı oluştuğunu bulmuş; diskin anteriorunun orta hattı uyarılınca da omuz ve sırt arasında ağrı olduğunu belirtmiştir. C6-C7 kaynaklı ağrının skapulanın alt kısmında, C5-C6 kaynaklı ağrının ise skapula mediyalinin ortasında hissedildiğini bildirmiştir. C4-C5 kaynaklı ağrılar, omurga çevresinde ve skapulanın superiorunda; C3-C4 kökenli ağrılar ise, C7 vertebranın spinöz çıkıntısı ve trapezius kasının posterior kenarında hissedilir.

Cloward aynı zamanda, posterolateral disk protrüzyonunda yansıyan ağrının anterior disk basılarında görülenden daha yoğun hissedildiğini ve ağrının skapulanın vertebral hatta yakın kısmından omuza ve kolun üst kısmına kadar yayılabildiğini göstermiştir. Posterior orta hat disk basılarında ise, ağrılar C5-T2 spinöz çıkıntıları arasında sınırlı bir yayılım gösterir. Yoğun disk rüptürü ve dejenerasyonu varsa, posterolateral ve orta hat bastlarına ait bulgular birlikte görülebilir. ${ }^{[13]}$ Öykü sorgulanırken; 50 yaş üzerinde olmak, kanser öyküsü, açıklanamayan kilo kaybı, istirahat ağrısı ve konservatif tedavide başarısızlık durumları, malignite için risk faktörleridir. Ayrıca, geçirilmiş enfeksiyon, diş müdahaleleri, ateş ve intravenöz ilaç kullanımı da sorgulanmalıdır. ${ }^{[14]}$ Alkoltütün kullanımı, ilaç bağımlılığı, osteoporoz, romatolojik hastalıklar ve nöropati yapabilen durumlar (vitamin eksiklikleri ve tiroid hastalıkları), ekarte edilmeli, eski muayene ve tedaviler gözden geçirilmelidir.

\section{FiZiK MUAYENE}

\section{Gözlem}

Fiziksel muayene gözlemle başlamalıdır. Gözlem, normal konuşma anında başın ve boynun postürünü ve hareketini içerir. Tipik olarak, hastalar kafalarını sakatlanmanın olduğu yandan diğer yana eğer ve boyunlarını dik tutarlar.

Aktif hareket açıklığı, özellikle etkilenmiş sinir kökü yönüne ya da diğer yöne doğru ekstansiyon, rotasyon ve yana eğme halinde azalmıştır. Etkilenen taraftan diğer tarafa doğru yana eğmeyle artan ağrı fitığın bir sinir köküne artan basısından kaynaklanabilirken, ipsilateral ağrı nöral foramen bölgesinde bir sinir kökünün sıkışmasına işaret eder.

\section{Elle Muayene}

Elle muayene (palpasyon), genellikle servikal paraspinal kaslar boyunca yapılır ve etkilenmiş sinir kökünün ipsilateral tarafi boyunca hassasiyet genellikle daha belirgindir. 
Kas hassasiyeti, semptomların iletildiği kaslar boyunca mevcut olabilir (örneğin; mediyal skapula, proksimal kol, lateral epikondil).

Ağrılı kaslarda elle muayene ile ilişkili hipertonisite ya da spazm meydana gelebilir.

Letchuman ve arkadaşları, servikal radikülopatinin, özellikle tutulu sinir köküyle sinir sistemine bağIı kaslara doğru bir eğilimle, radikülopati tarafında hassas noktaların (gerek tetik noktaları gerekse hassas noktalar) artmasıyla ilişkili olduğunu göstermişlerdir. ${ }^{[15]}$ Bu çalışma, radikülopatide sadece ağrıdan değil aynı zamanda hassasiyetten de bahsedilebileceğini göstermiştir.

\section{Motor Muayene}

Elle kas değerlendirmesi, etkilenmiş bir sinir kökünün derecesini belirmenin önemli bir yoludur. Miyotomal bir dağılımda anlaşılması zor bir güçsüzlüğü tespit etmek için, elle kas değerlendirmesi gerçekleştirilmelidir. Etkilenen taraftaki uzvu (kol ya da bacak) yerçekiminin aksi yönüne yerleştirip, bir sonraki distal ekleme proksimal olarak direnç uygulamak gerekir. Örneğin; ekstansör karpi ulnaris kasını test etmek için, hastanın önkolu tam pronasyon pozisyonuna getirilir ve bir masaya koyulur ya da destekleyip hastaya elini uzatması ve elini ulnar tarafa saptırması talimatı verilirken muayeneyi gerçekleştiren kişi de beşinci metakarpal kemiğin dorsumuna doğru direnç uygulayarak, kas gücü 0'dan 5'e kadar bir ölçekte puanlanır:

0- Kas kontraksiyonu yok.

1- Kas kontrakte oluyor ama eklemi/uzvu hareket ettiremiyor.

2- Kas eklemi/uzvu hareket ettirebiliyor, ancak yerçekimine karşı hareket ettiremiyor.

3- Kas eklemi/uzvu yerçekimine karşı hareket ettirebiliyor, ancak tam hareket açıklığı boyunca ettiremiyor.

4- Kas eklemi/uzvu tam hareket açıklığı boyunca hareket ettirebiliyor, ancak dirence karşı güç diğer uzva (eğer normal ise) eşit değil.

5- Kas gücü normal (diğer, normal uzva eşit).

\section{Sinir Seviyesine Göre Radikülopatiler}

\section{C5 radikülopati}

- Zayıflık: omuz abduksiyonu

- Test: Hastalara, muayeneyi gerçekleştiren kişinin aşağı doğru gücüne karşı omuzlarını abduksiyonda tutturun.

\section{C6 radikülopati}

- Zayıflık: dirsek fleksiyonu, bilek ekstansiyonu

- Test: Hastalara, muayeneyi gerçekleştiren kişinin direncine karşı kollarını kaldırtın.

\section{C7 radikülopati}

- Zayıflık: dirsek ekstansiyonu, bilek fleksiyonu

- Test: Hastalara, kolları göğüslerinden uzak, muayeneyi gerçekleştiren kişinin direncine karşı itmelerini söyleyin.

\section{C8 radikülopati}

- Zayıflık: başparmak ekstansiyonu, bilek ulnar deviyasyonu

- Test: Hastalardan açılmış parmaklarını muayeneyi gerçekleştiren kişinin parmakları açma girişimlerine karşı birlikte tutmalarını isteyin.

\section{Duyusal Muayene}

Duyu muayenesi üzerine, belirgin bir radikülopatisi olan hastalar dermatomal dağııımda bir duyu azalması ya da duyu kaybı gösterecektir.

Ayrıca, radikülopatisi olan hastaların hafif dokunmaya ve iğneleme muayenesine karşı aşırı duyarlılıkları olabilir. Duyu muayenesi hasta tarafından bir yanıt gerektirdiği için oldukça subjektif olabilir.

\section{Derin Tendon Refleksleri}

Muayeneyi gerçekleştiren kişi bu refleksleri elde ederken uzvu doğru bir biçimde konumlandırmalı, hasta da mümkün olduğunca relakse (gevşemiş) olmalıdır. Herhangi bir refleks derecesi normal olabilir; bu yüzden reflekslerin asimetrisi en yararlı bulgudur.

Biseps braki refleksi, antekübital çukurdaki distal tendona hafifçe vurularak elde edilir. Bu refleks C5-C6 seviyesinde gerçekleşir.

Brakiyoradiyalis refleksi, bileğin radyal yönüne hafifçe vurularak elde edilir. Bu da bir C5-C6 refleksidir. Triseps refleksi, dirsek $90^{\circ}$ 'lik fleksiyon halinde relakse iken, dirseğin posterior yönünün distal tendonuna hafifçe vurarak elde edilebilir. Bu C7-C8 sinir köklerini test eder.

Pronator refleksi, C6 ve $\mathrm{C7}$ sinir kökü sorunlarının ayırt edilmesinde yararlı olabilir. Eğer bu refleks anormal bir triseps refleksiyle birlikte anormal ise, o zaman tutulma seviyesinin C7 olması daha olasıdır. Pronator refleksi, önkol nötr bir pozisyonda ve dirsek flekse haldeyken distal radiusun volar yüzüne hafifçe vurularak elde edilir. Bu, pronator teresin gerilmesine neden olur ve bu da, bir refleks pronasyonuyla sonuçlanır. 


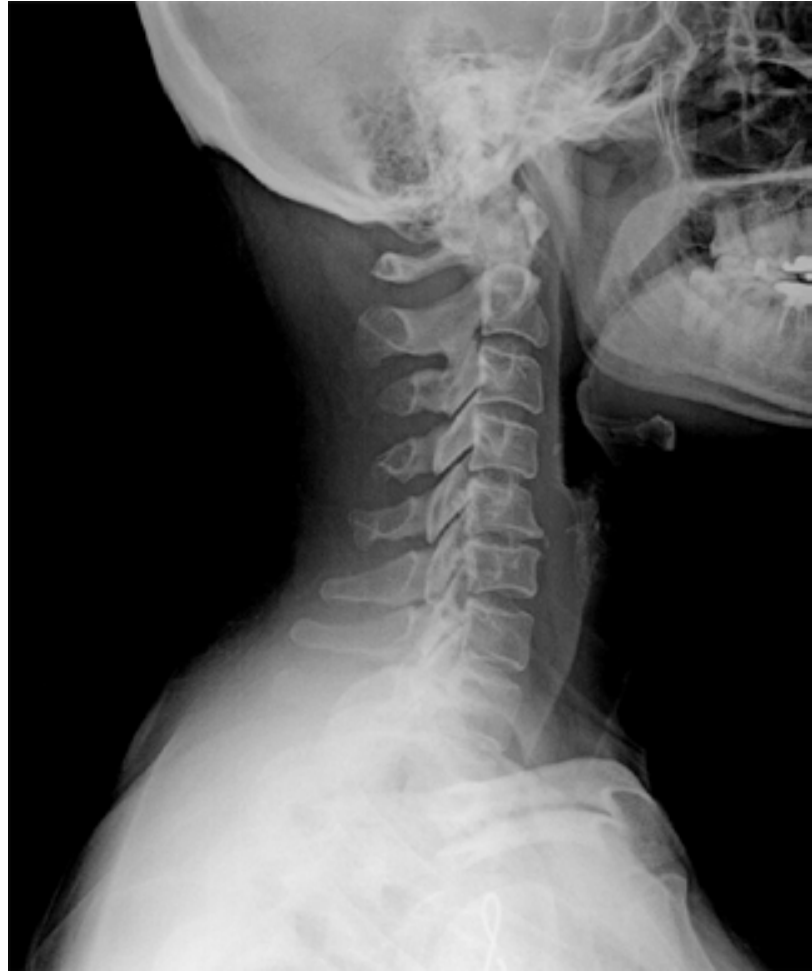

Şekil 1. Servikal diskopatili hastanın uzun süren semptomlarının, boyunda lordoz azalması ve düzleşmeye neden olması.

\section{Tetikleyici (Provokatif) Testler}

Foraminal kompresyon testi, ya da Spurling testi, servikal radikülopati tanısını teyit etmek için kullanılabilir. Hastayı boyun uzatılmış ve kafa ağıı olan tarafa döndürülmüş biçimde konumlandırıp, daha sonra başa aşağı doğru baskı uygulayarak gerçekleştirilir. Eğer ağrı başın dönük olduğu yöne, ipsilateral uzva yansırsa, test pozitif sayılır. Akut radikülopati tanısı koymada Spurling testinin çok özgül olduğu (\%93) ancak duyarlı (\%30) olmadığı görülmüştür. ${ }^{[16]}$ Bu nedenle, bu test bir tarama testi olarak yararlı değildir, ancak servikal radikülopatinin teyit edilmesi için klinik olarak yararlıdır. ${ }^{[17]}$

Manuel servikal distraksiyon, bir fiziksel muayene testi olarak kullanılabilir. Hasta sırtüstü pozisyondayken, hafif manuel distraksiyon radikülopatisi olan hastalarda boyun ve kol semptomlarını büyük ölçüde azaltır.

\section{GÖRÜNTÜLEME ÇALIŞMALARI}

\section{Direkt Radyografi}

Direkt radyografi, ilişkili kemik yaralanmasını göstermek için yararlı bir tarama aracıdır. Kronik disk dejenerasyonunda disk yüksekliği azalması görülmesine karşın, düz filmlerin akut disk yaralanmalarına sekonder disk yüksekliği azalmasını göstermesi kesin değildir. Bunula birlikte, uzun süren semptomlar boyunda lordoz azalması ve düzleşmeye neden olabilir (Şekil 1). Bu durum da düz grafilerde kolayca tespit edilir.

\section{Miyelografi}

Intervertebral disk seviyesinde ekstradural defekt olur. Kökün izlediği yolda kesinti olur.

\section{Tomografi}

Ventral epidural yumuşak doku dansitesi, disk ile devamlılık olacak şekilde spinal kanal içerisine doğru genişler. Tekal sak bozulur ve çıkan kök deplase olur.

\section{MR}

Servikal disk herniyasyonunda radyolojik tanımlamaları bilmek önemlidir. Servikal disk protrüzyonu, ekstrude disk, serbest fragman ve sekestre disk tanımlarının hepsinde, disk vertebral halka apofizinin ilerisine taşmış, deplase olmuştur. Servikal disk herniyasyonu tüm tanımlamaları kapsar. Kanal içi parça intervertebral disk ile devamlılıkta gösterebilir (protrüzyon), ayrı kopmuş bir parçada olabilir (sekestre ya da serbest parça).

Genel olarak servikal disk herniyasyonu, en sık C6C7 seviyesindedir ve C7 kökü basılıdır. C5-C6 en sık ikinci yerdir ve C6 kökü etkilenmiştir.

MR en sık kullanılan görüntüleme metodudur. Net biçimde kök ya da kord basısı oranı görüntülenir (Şekil 2). Sagittal ve aksiyel görüntüler mutlaka alınmalıdır. Tümör ya da enfeksiyon düşünülen durumlarda, intravenöz kontrastlı görüntüler de elde edilmelidir.

MR, disk yüksekliği azalması ve sinyal yoğunluğu azalmasının yanı sıra spondilotik spurları da gösterebilir; disk hernisine sekonder omurilik ya da sinir kökü sıkışmasının değerlendirilmesi açısından daha da önemlidir. Asemptomatik bireylerde birçok anormal MR bulgusu fark edildiğinden, MR görüntülerinin yorumlanması önemlidir. ${ }^{[18]}$

\section{Diğer Testler}

Klinikve radyolojik bulguları ilişkilendirmek için elektrodiyagnostik çalışmalar gerekli olabilir. Konservatif önlemlere cevap vermeyen, inatçı aksiyel boyun ağrısında diskografi endikedir. Diskografi tetikleyici bir işlem olup, hastanın ağrı kompleksini yeniden yaratmak için alt servikal disklere normal salin enjekte edilerek gerçekleştirilir. 

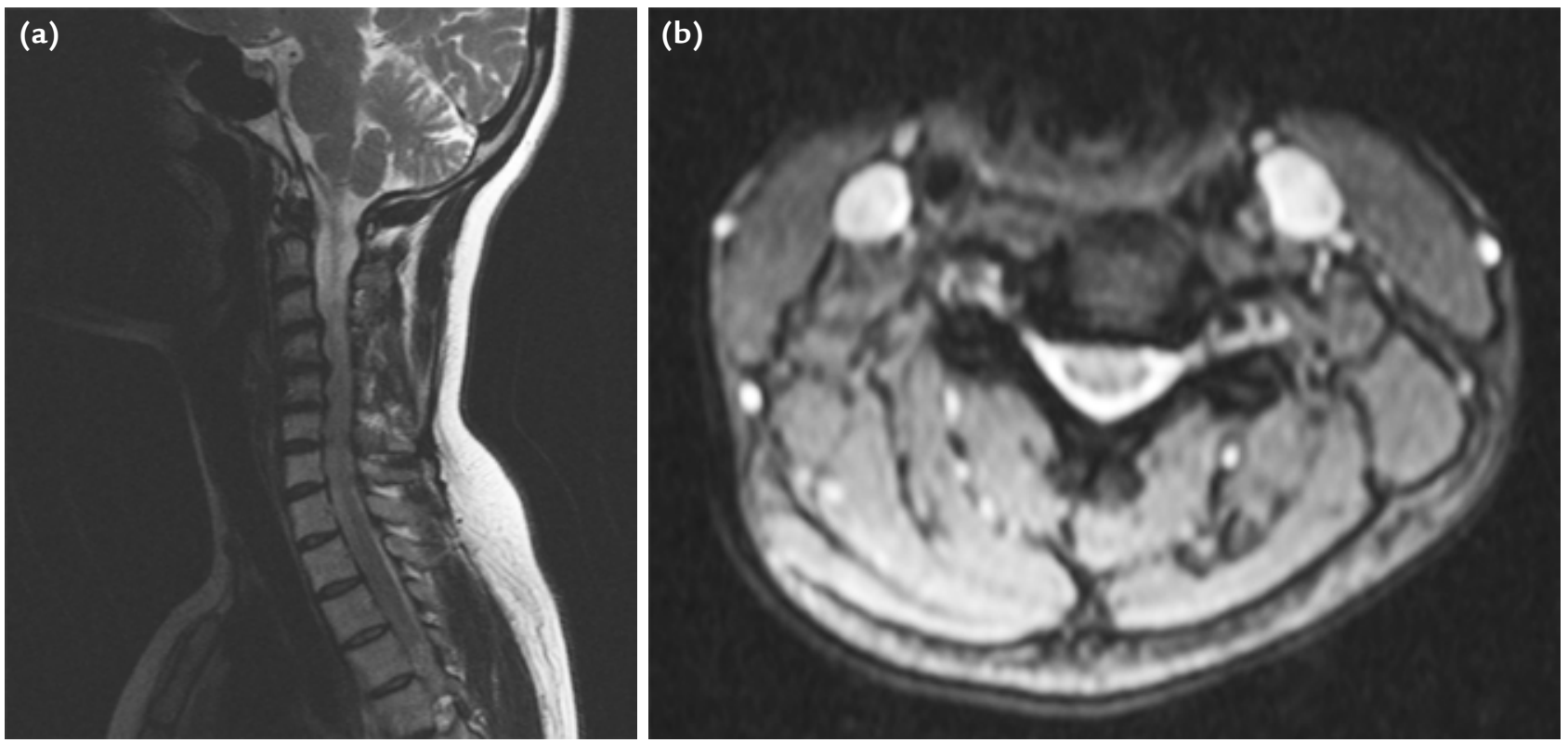

Şekil 2. a, b. Servikal diskopatili hastanın sagittal (a) ve aksiyel (b) MR kesitleri.

\section{TEDAVi}

\section{Konservatif Tedavi}

Servikal disk ağrısı tedavisi, klinik bulgulara ve birlikte olan diğer tıbbi durumlara bağlıdır. Çoğu servikal disk hernisi, agresif konservatif tedaviyle çözümlenebilir. Ilaç olarak NSAii, kısa süreli steroidler, antidepresanlar, antiepileptik ilaçlar ve nöroleptikler, narkotik olmayan analjezikler ve kısa süreli narkotikler kullanılabilir. Beraberinde kısa süreli istirahat ve sonrasında postür eğitimi ve ev egzersizleri önerilir. ${ }^{[19,20]}$ Radikülopatisi olmayan hastalarda, tedavi programı, postür eğitimi ve vücut biyomekaniği için özel egzersizlere yoğunlaşılmalıdır.

Servikal omurganın değerlendirilmesi ve tedavisinde kullanılan McKenzie metodu, omurganın temel olarak her yöne yapılan basit hareketlerini, temel ağrı düzeyini, distal ve periferal semptomları, hareketle olan değişiklikleri içerir. Mobilizasyon ve manipülasyon için güç uygulanacaksa bu metoda başvurulur. ${ }^{[2,21]}$ Temel hareket açıklığı elde edilince, her yöne tekrarlayan hareketler yaptırılarak son hareket açıklığına ulaşılırken, başlangıçtaki semptomların da değiştiği gözlenir. Tekrarlayan hareketlerle ağrı ve semptomlar artıyorsa, hareketlere hemen son verilmelidir. ${ }^{[2,3,21]}$

Radiküler semptomları olan hastalarda santralizasyon fenomeni görülebilir. McKenzie bu durumu tanımlarken, ağrının tekrarlayan hareketlerde, bazı pozisyonlardan sonra oluşmasını ve ağrının omurga kaynaklı mı yoksa yansıyan ağrı mı olduğunu göz önünde tutmuştur. Santralizasyon, yapılan hareketin veya pozisyonun doğruluğu için iyi bir işaret, periferalizasyon ise hareket ağırlığını arttırmak için kontrendikasyon teşkil eder.[2,21]

\section{Diğer Tedaviler}

İlaç tedavisine, traksiyona ve iyi tasarlanmış bir fizik terapi programına tatmin edici bir yanıt vermemiş hastalarda, servikal epidural steroidler kullanılmaktadır. ${ }^{[22,23]}$ Deneyimli doktorlar tarafindan ve floroskopi kılavuzluğunda doğru bir şekilde uygulandığında, önemli sayıda hastanın servikal radikülopatisi, diğer tedavilerin yardımcı olmadığı durumlarda, servikal epidural steroidlere cevap vermektedir. Amerikan Girişimsel Ağrı Hekimleri Derneği de, servikal interlaminar epidural steroid enjeksiyonlarının, servikal radikülopatide kısa ve uzun süreli iyileşme sağlayabileceği konusunda orta düzey kanıt bulmuştur. ${ }^{[24]}$

Çalışmalar, translaminar ve transforaminal epidural kortikosteroid enjeksiyonlarıla ilgili olumlu sonuçlar bildirmiştir. Bu çalışmalar, radiküler ağrı ve boyun ağrılarında \%60'a kadarlık bir uzun vadeli rahatlama olduğunu ve hastaların olağan aktivitelerine geri döndüklerini göstermektedir. Bu prosedürlerin neden olduğu komplikasyonlar nadirdir, ancak bazı olgu çalışmaları komplikasyonların katastrofik olabileceğini ve spinal korddan ya da beyin sapı enfarktüsünden şiddetli sekelleri içerebileceğini göstermektedir. Enjeksiyonlar, 

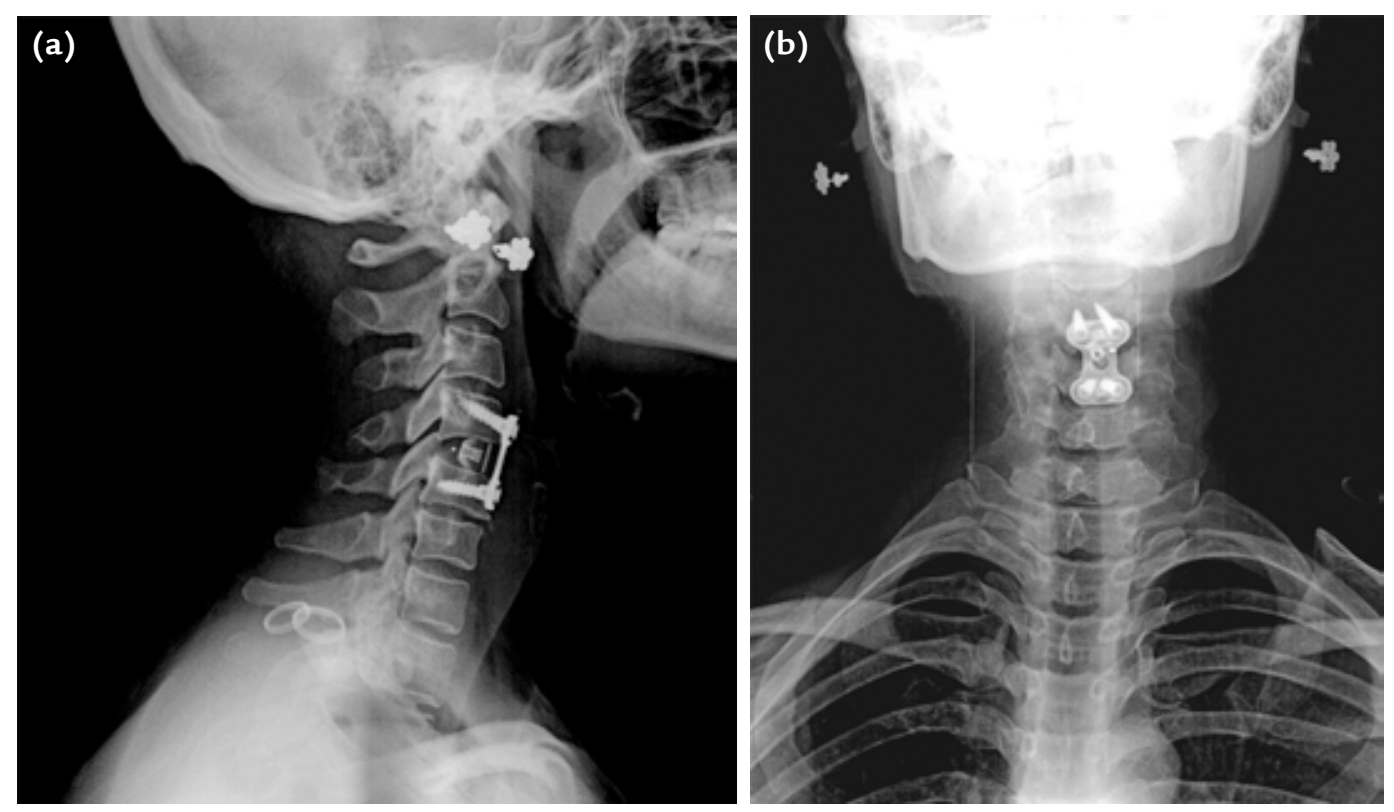

Şekil 3. a, b. Servikal diskopati nedeniyle anterior servikal diskektomi ve füzyon işlemi sonrasında AP (a) ve lateral (b) X-ray görüntüsü.

oral ilaç tedavisi kürüne, aktif fizik tedaviye ve rölatif istirahate yanıt vermemiş dirençli radiküler ağrısı olan hastalara yönelik olmalıdır. Bu enjeksiyonların "dizi" halinde uygulanmasına ilişkin hiçbir endikasyon yoktur. Olguların çoğunda, sinir kökü inflamasyonunu azaltmak ve hastayı aktif bir egzersiz programına geçirmek için, sadece 1-2 enjeksiyon gereklidir.

Engel ve arkadaşları, radiküler ağıı tedavisinde kortikosteroidlerin floroskopik rehberlik altında servikal transforaminal enjeksiyonun etkinliğini ve risklerini incelemek için sistematik bir literatür incelemesi gerçekleştirmişlerdir. ${ }^{[25]}$ Araştırmacılar, hastaların yaklaşık \%50'lik bir bölümünün servikal transforaminal steroid enjeksiyonu sonrasında, en az dört hafta süreyle, radiküler ağrıda \%50'lik rahatlama yaşadıklarına ve müdahalenin cerrahiye olan ihtiyacı azaltan etkileri olduğuna işaret eden kanıtlar bulmuşlardır. Literatür ayrıca, 13 ölüm ve çok sayıda katastrofik nörolojik yaralanma da dahil olmak üzere, komplikasyonlar bildiren 21 adet de makale içermektedir. Yazarlar, servikal radiküler ağrısı olan hastalarda floroskopik rehberlik altında servikal transforminal steroid enjeksiyonunun, ağrının hafifletilmesinde ve cerrahi ihtiyacının azaltılmasında etkili olabileceği sonucuna varmışlardır. Ancak, etkililik kanıtının kalitesi çok düşüktür ve ciddi komplikasyon riskleri, prosedürün yararlarını tehlikeye atmaktadır.

Akupunktur, radiküler ağrı tedavisi amacıyla bir miktar başarıyla kullanılmaktadır. Eğer fizik tedavi ve ilaç tedavisiyle ya da bu tedavilerin birlikte uygulanmasıyla ağrı kontrolü elde edilemediyse, bu tedavi düşünülebilir. Ayrıca, servikal epidural enjeksiyon prosedürü konusunda tereddütlü ya da bu prosedüre başlamak istemeyen hastalarda, servikal epidüral enjeksiyon yerine denenebilir. ${ }^{[26]}$

Başka bir çalışma, servikal dorsal kök gangliyonunun atımlı radyofrekans tedavisinin, kronik servikal radiküler ağrısı olan ve özenle seçilmiş sınırlı sayıda hasta için ağrı rahatlaması sağlayabileceği sonucuna varmıştır. ${ }^{[27]}$

\section{Cerrahi Tedavi}

Kapsamlı bir rehabilitasyon programı ve selektif enjeksiyonlarla durumlarında iyileşme olmayan hastalara, cerrahi girişim önerilmelidir. Genellikle, hastaların konservatif tedavi ile ilk 6-8 haftada ilerleyici iyileşme göstermesi beklenir. Eğer bu zaman dilimi içinde anlamlı bir ilerleme yoksa, cerrahi bir girişimi göz önünde bulundurmak gerekir.

Hastaların servikal instabilitesi olduğu durumlarda, erken cerrahi girişim tavsiye edilir. Ayrıca, progresif nörolojik defisit belirtileri olan hastalarda da cerrahi düşünülmelidir.

Cerrahi girişim en çok, öykü ve fiziksel muayenedeki verilerle benzerlik gösteren tek seviyeli disk hernisi gibi, açık bir biçimde tanımlanmış bir patolojiye sahip hastalarda endikedir.

Servikal prosedürler; anterior diskektomi ve füzyon (anterior plak-vida ile kombin edilebilir, Şekil 3), 
hemilaminektomi ve foraminotomi, füzyon olmaksızın anterior diskektomi, korpektomi ve füzyonu içerir. Uygun endikasyonlarla, cerrahi hastaların çoğunluğunda semptomlarda çözülme ve mükemmel sonuçlar elde edilmektedir.

Yapay disk konsepti ile anterior servikal dekompresyon ve füzyonla tedavi konseptinin sonuçlarını karşılaştıran bir çalışma, yapay disk replasmanının, cerrahiden iki yıl sonra anterior servikal dekompresyon ve füzyonla tedaviye kıyasla daha iyi bir sonuca sahip olmadığını göstermiştir. ${ }^{[28]}$

\section{PROGNOZ}

Akut radikülopati, genellikle kendi kendini sınırlayan ve tam iyileşmesi beklenen bir rahatsızlıktır. Kronik nonspesifik ağrılı hastaların \%90'ı üç ay içinde işlerine dönebilmektedirler. Ancak, hastaların \%30'unda tekrarlayan ya da devam eden dirençli ağrılar da görülebilir.

\section{KOMPLIKASYONLAR}

Komplikasyonlar; yetersiz nörolojik iyileşme, servikal hareket açıklığı kaybı, disk alanı daralması gösteren radyografik değişiklikler, persistan normal servikal lordoz kaybı, ve/veya osteofit oluşumunu içerir.

\section{KAYNAKLAR}

1. Hult L. Cervical, dorsal and lumbar spinal syndromes; a field investigation of a non-selected material of 1200 workers in different occupations with special reference to disc degeneration and so-called muscular rheumatism. Acta Orthop Scand Suppl 1954;17:1-102.

2. McKenzie R. The Cervical and Thoracic Spine. Mechanical Diagnosis and Therapy. Wakainae, New Zealand: Spinal Publications New Zealand Limited; 1990.

3. Kramer J. Intervertebral Disk Diseases. Causes, Diagnosis, Treatment and Prophylaxis. George Thieme Verlag, Stuttgart Year Book, Medical Publishers Inc.; 1981.

4. Bailes JE, Maroon JC. Management of cervical spine injuries in athletes. Clin Sports Med 1989;8(1):43-58.

5. Maroon JC, Steele PB, Berlin R. Football head and neck injuries -an update. Clin Neurosurg 1980;27:414-29.

6. Cantu RC. The cervical spinal stenosis controversy. Clin Sports Med 1998;17(1):121-6.

7. Bogduk N, Twomey LT. Clinical Anatomy of the Lumbar Spine, 2nd ed. Melbourne, Australia: Churchill Livingstone; 1991.

8. Saal JS, Franson RC, Dobrow R, Saal JA, White $A H$, Goldthwaite N. High levels of inflammatory phospholipase A2 activity in lumbar disc herniations. Spine (Phila Pa 1976) 1990;15(7):674-8.

9. Ordway NR, Seymour RJ, Donelson RG, Hojnowski LS, Edwards WT. Cervical flexion, extension, protrusion, and retraction. A radiographic segmental analysis. Spine (Phila Pa 1976) 1999;24(3):240-7.
10. Ellenberg MR, Honet JC, Treanor WJ. Cervical radiculopathy. Arch Phys Med Rehabil 1994;75(3):342-52.

11. White AA, Panjabi MM. Clinical Biomechanics of the Spine, 2nd ed. Philadelphia, Pa:J.B. Lippincott Co.; 1990. p.85-125.

12. Harms-Ringdahl K. On assessment of shoulder exercise and load-elicited pain in the cervical spine. Biomechanical analysis of load -EMG- methodological studies of pain provoked by extreme position. Scand J Rehabil Med Suppl 1986;14:1-40.

13. Cloward RB. Cervical diskography. A contribution to the etiology and mechanism of neck, shoulder and arm pain. Ann Surg 1959;150:1052-64.

14. Deyo RA, Rainville J, Kent DL. What can the history and physical examination tell us about low back pain? JAMA 1992;268(6):760-5.

15. Letchuman R, Gay RE, Shelerud RA, VanOstrand LA. Are tender points associated with cervical radiculopathy? Arch Phys Med Rehabil 2005;86(7):1333-7.

16. Tong HC, Haig AJ, Yamakawa K. The Spurling test and cervical radiculopathy. Spine (Phila Pa 1976) 2002;27(2):156-9.

17. Nordin M, Carragee EJ, Hogg-Johnson S, Weiner SS, Hurwitz EL, Peloso PM, Guzman J, van der Velde G, Carroll LJ, Holm LW, Côté P, Cassidy JD, Haldeman S; Bone and Joint Decade 2000-2010 Task Force on Neck Pain and Its Associated Disorders. Assessment of neck pain and its associated disorders: results of the Bone and Joint Decade 2000-2010 Task Force on Neck Pain and Its Associated Disorders. Spine (Phila Pa 1976) 2008;33(4 suppl):S101-22. Crossref

18. Nakashima H, Yukawa $Y$, Suda K, Yamagata M, Ueta $T$, Kato $F$. Abnormal findings on magnetic resonance images of the cervical spines in 1211 asymptomatic subjects. Spine (Phila Pa 1976) 2015;40(6):392-8. Crossref

19. Gangi A, Tsoumakidou G, Buy X, Cabral JF, Garnon J. Percutaneous techniques for cervical pain of discal origin. Semin Musculoskelet Radiol 2011;15(2):172-80. Crossref

20. Manchikanti L, Abdi S, Atluri S, Benyamin RM, Boswell MV, Buenaventura RM, Bryce DA, Burks PA, Caraway DL, Calodney AK, Cash KA, Christo PJ, Cohen SP, Colson $J$, Conn A, Cordner H, Coubarous S, Datta S, Deer TR, Diwan S, Falco FJ, Fellows B, Geffert S, Grider JS, Gupta $\mathrm{S}$, Hameed $\mathrm{H}$, Hameed $\mathrm{M}$, Hansen $\mathrm{H}$, Helm S 2nd, Janata JW, Justiz R, Kaye AD, Lee M, Manchikanti KN, McManus CD, Onyewu O, Parr AT, Patel VB, Racz GB, Sehgal N, Sharma ML, Simopoulos TT, Singh V, Smith HS, Snook LT, Swicegood JR, Vallejo R, Ward SP, Wargo BW, Zhu J, Hirsch JA. An update of comprehensive evidence-based guidelines for interventional techniques in chronic spinal pain. Part II: guidance and recommendations. Pain Physician 2013;16(2 Suppl):S49-283.

21. Donelson R, Aprill C, MedcalfR, Grant W. A prospective study of centralization of lumbar and referred pain. A predictor of symptomatic discs and anular competence. Spine (Phila $\mathrm{Pa}$ 1976) 1997;22(10):1115-22.

22. Cohen SP, Gupta A, Strassels SA, Christo PJ, Erdek MA, Griffith SR, Kurihara C, Buckenmaier CC 3rd, Cornblath D, Vu $\mathrm{TN}$. Effect of MRI on treatment results or decision making in patients with lumbosacral radiculopathy referred for epidural steroid injections: a multicenter, randomized controlled trial. Arch Intern Med 2012;172(2):134-42. Crossref

23. Friedly J, Deyo RA. Imaging and uncertainty in the use of lumbar epidural steroid injections: comment on "effect of MRI on treatment results or decision making in patients with lumbosacral radiculopathy referred for epidural steroid injections". Arch Intern Med 2012;172(2):142-3. Crossref 
24. American Society of Interventional Pain Physicians. An update of comprehensive evidence-based guidelines for interventional techniques in chronic spinal pain. Part II: guidance and recommendations. National Guideline Clearinghouse. Available at: http://guideline.gov/summaries/ summary/45379. Accessed: April 20, 2017.

25. Engel A, King W, MacVicar J; Standards Division of the International Spine Intervention Society. The effectiveness and risks of fluoroscopically guided cervical transforaminal injections of steroids: a systematic review with comprehensive analysis of the published data. Pain Med 2014;15(3):386402. Crossref

26. Council of Acupuncture and Oriental Medicine Associations (CAOMA), Foundation for Acupuncture Research. Acupuncture and electroacupuncture. Evidence-based treatment guidelines. Calistoga (CA): Council of Acupuncture and Oriental Medicine Associates (CAOMA); 2004. https:// guideline.gov/summaries/archive/withdrawn/1842\#jumptoC [Withdrawn]
27. Van Zundert J, Patijn J, Kessels A, Lamé I, van Suijlekom H, van Kleef M. Pulsed radiofrequency adjacent to the cervical dorsal root ganglion in chronic cervical radicular pain: a double blind sham controlled randomized clinical trial. Pain 2007;127(1-2):173-82. Crossref

28. Skeppholm M, Lindgren L, Henriques T, Vavruch L, Löfgren $H$, Olerud $C$. The Discover artificial disc replacement versus fusion in cervical radiculopathy -a randomized controlled outcome trial with 2-year follow-up. Spine J 2015;15(6):128494. Crossref 